\title{
INTEGRATED SYSTEMATIC REVIEW ON EDCUATIONAL STRATEGIES THAT PROMOTE ACADEMIC SUCCESS AND RESILIENCE IN UNDERGRADAUTE INDIGENOUS STUDENTS
}

\section{Introduction}

Globally, there is little question that education can be transformative towards ‘closing the gap’ agenda and improving the socio-economic position of Indigenous peoples (Hossain, Gorman, WilliamsMozely, \& Garvey, 2008; Pechenkina, Kowal, \& Paradies, 2011; Rossingh \& Dunbar, 2012). The negative impact of colonisation on the health and wellbeing of Indigenous peoples around the world is indisputable. In countries like Australia, New Zealand (NZ) and Canada, health disparities between Indigenous and non-Indigenous people are well documented (Australian Institute of Health and Welfare, 2015; New Zealand Ministry of Health, 2014; Government of British Columbia, 2013). Alongside numerous reports of health disparities are recommendations about the essential role Indigenous health workers have in the provision of healthcare to their own people. However, in order to improve health outcomes and establish parity for Indigenous peoples in leadership roles across all health professions, higher education must be seen as a natural pathway.

Despite the myriad of recommendations, education providers continue to struggle to demonstrate valuing the world views and perspectives of Indigenous peoples in flexible, responsive and inclusive ways (Behrendt, Larkin, Griew, \& Kelly, 2012). There is a dearth of evidence around educational strategies that address the adverse academic experiences of Indigenous students. The purpose of this review is to examine available research on effective educational strategies that support Indigenous student success in undergraduate programs in higher education.

\section{Indigenous student success in undergraduate programs}

An analysis of data from the Commonwealth Department of Education (2012) Canadian Government (Government of British Columbia, 2013) and the United States of America (USA) (Inglebret \& Krebill-Prather, 2011) indicates that little has changed over the last decade to address poor Indigenous student outcomes. In Australia, for example, there has been little change to participation rates with only $1.2 \%$ of all commencing higher education students identifying as Indigenous (Commonwealth Department of Education, 2013). In New Zealand although participation rates have increased from $11 \%$ to $13 \%$ for Māori students and 13\% to 16\% for Pasifika students, these groups are still underrepresented compared to their non-Indigenous peers (29\% versus 54\%) (Curtis et al., 2012). Furthermore, less than $50 \%$ of commencing Indigenous students complete their undergraduate programs, compared with 72\% for non-Indigenous students (Asmar, Page \& Radloff, 2011).

The transition to higher education for Indigenous students can be difficult (Oliver, Rochecouste, Anderson, Forrest, \& Excell, 2013). Page, DiGregorio and Farrington (1997) found that educational strategies that support success had various characteristics. Successful strategies acknowledged students' Indigenous culture; recognised students as novice university learners, prioritised family support for students, and encouraged participation in study groups. Research has also found that 
Indigenous students are more likely to succeed in universities where acknowledgement is given to the importance of sharing responsibilities, partnerships, and the establishment of Indigenous education support units (IESU’s) (Oliver et al., 2013).

In New Zealand the national government has stated its responsibility to work collaboratively with Indigenous communities to effect change (New Zealand Government, 2014). By embedding strategies into legislation to improve student outcomes, the State acknowledges the rights of Indigenous people and recognises the economic benefits to individuals and society from improved levels of education (New Zealand Government, 2014). Such strategies have been making small increases to Indigenous student participation levels in higher education but are yet to show marked increases in successful completion rates (New Zealand Government, 2014).

\section{Critical framework for this review}

Traditionally, systematic reviews in education use a structured framework to critique interventions, measures and tools. For example, Preferred Reporting Items for Systematic Reviews and MetaAnalysis (PRISMA) (Moher, Liberati, Tetziaff \& Altman, 2009) and Critical Appraisal Skills Program (CASP) (CASP, 2014) were considered but deemed to not be culturally appropriate for the current review. An alternative framework of analysis was therefore developed and included components of Feminism (Harding, 2004), Indigenous (Martin, 2008; Moreton-Robinson, 2013), and Cultural (Bilic, 2012) Standpoint theories and is titled "Reframed Standpoint Theory" for the purpose of this review.

\section{Reframed Standpoint Theory}

A Standpoint Theory framework allows for flexibility and validation of the participant's voice (Martin, 2008). A combination of feminist, Indigenous and cultural standpoints were used to inform the current framework. Feminist Standpoint Theory emerged during the 1970s and 1980s from feminist critical theory and focused on the connection between the production of knowledge and practices of power (Harding 2004). It was also presented as a mechanism towards empowerment of oppressed groups, valuing their experiences and legitimising difference (Harding, 2004). More recently Indigenous researchers have begun to develop a Standpoint Theory that reflects their Indigenous cultures (Moreton-Robinson, 2000; Martin, 2008). Moreton-Robinson (2000) in her early discourse represented an Indigenous standpoint of Australian feminism, giving voice to Indigenous women, challenging the dominance of 'whiteness' and exposing this as a position of power and privilege. Both Martin (2008) and Morton-Robinson (2013) present a paradigm towards cultural safety by using the concepts of ontology (ways of being) epistemology (ways of knowing) and axiology (ways of doing).

As two of the authors are non-Indigenous researchers, consideration of these elements was deemed to be an important process in critiquing the studies in this review. The paradigm of Cultural Safety had its beginnings from a colonial context in response to the poor health of Māori people in New Zealand. Cultural safety places an obligation on the practitioner (such as a nurse, midwife, or educator) to provide care whilst recognising and respecting difference. The Cultural Safety paradigm also addresses 
power relationships between provider and user of the service. The person receiving the 'care' determines the extent to which they feel safe (Papps \& Ramsden, 1996). With cultural safety in mind the non-indigenous authors aimed to conduct a culturally safe integrative systematic review of the literature, whilst acknowledging their place of privilege and power and as outsiders trying to look in.

From a Cultural Safety paradigm perspective, Standpoint Theory is an appropriate framework from which to consider issues that stem from the tension between the dominant higher educational culture and Indigenous or First Nations students. The application of feminist, Indigenous and cultural standpoints allow for an interpretive flexibility when reviewing the literature while giving voice to participants from the included studies. Bilic (2012) used a Standpoint Theory as a framework for her research into the tensions between women's and cultural rights. Six elements of Standpoint Theory were used to scrutinise this issue; strong objectivity, double consciousness, heterogeneous women's experience, representation of other, reflexivity, and navigating outsider/ inside status within research. In the current review, these six elements have been integrated under the headings of: 'ways of being' including representation of other, 'ways of knowing' including heterogeneous women's experience and 'ways of doing' including strong objectivity, double consciousness, reflexivity and navigating outsider/insider to critique the included papers (Martin, 2008; Morton-Robinson, 2013).

\section{Search Procedure}

A search of four databases: Scopus, ProQuest, Informit and Web of Science was conducted between October 2014 to January 2015. A search of Google Scholar was also undertaken to locate any other relevant material from conference reports, government reports and other significant documents. Reference lists of all retrieved articles were scanned manually. The search was limited to English language and studies published from 1995 to 2015.

The inclusion criteria were: peer reviewed research articles from scholarly journals that referenced Indigenous, Aboriginal, First Nation or Māori students. The most commonly used term in research with 'First Peoples' is Indigenous. It is with the utmost respect that this term is used in this review whilst acknowledging that Indigenous people in different countries have their own preferred identity, for example, Aboriginal and Torres Strait Islanders in Australia, Māori in New Zealand, and First Nations in Canada.

The search terms were used individually and in combination (including and/or) and applied to the title, abstract and body of all works. The search was conducted sequentially using the data base search engines and combinations of key search terms. These results are presented in Table 1 (search results). After applying all search terms sequentially 156 articles were located across all four databases; a filter was applied to remove any that did not focus on higher education. This final search revealed 24 research papers and 11 Government reports which were saved into a standard software tool for managing citations and references (Endnote X7). Government reports were used for reference purposes only. The remaining articles were evaluated to assess relevance according to the search criteria and 
reveal duplication. Fifteen articles were excluded during this process. Reference lists were scanned and a further three papers were retrieved, and a manual search resulted in four more papers.

\section{Results}

The results are presented according to elements of the Reframed Standpoint Theory in regard to 'ways of being' 'ways of knowing' and 'ways of doing'. A total of 16 research papers met the inclusion criteria and are presented in Table 2. Included papers were summarised under the following headings of author/year/country, research design, education approach/strategy, tools/measures, ways of being, ways of knowing, ways of doing, implications for nursing and midwifery education and limitations.

\section{Research design}

A qualitative research design was used in 11 of the 16 research papers (Adams et al., 2005; Plater, 2013; Oloo, 2007; Usher, Lindsay, Miller \& Miller, 2005; Kippen, Ward \& Warren, 2006; Digregorio, Farrington \& Page, 2000; West, Usher, Foster \& Stewart, 2014; Bingham, Bearchief Adolpho, Jackson, Alexitch, 2014; Day \& Nolde, 2009; Hall, Rata \& Adds, 2013; Craven \& Dillon 2013), four were mixed methods (West, Usher, Buetther, Foster \& Stewart, 2013; Asmar et al., 2011; Oliver et al., 2013; Bennett et al., 2002), and a quantitative research method was used in one study (Pechenkina, Kowal \& Paradies, 2011).

\section{Ways of Being}

For the purposes of this review, sample characteristics were included under 'ways of being', which acknowledges the cultural diversity of participants across the included papers. Eleven studies were undertaken in Australia (Adams et al., 2005; Plater, 2013; Usher et al., 2005; Kippen et al., 2006; Digregorio et al., 2000; West et al., 2014; Day et al., 2009; Craven \& Dillon, 2013; West et al., 2013; Oliver et al., 2013; Pechenkina et al., 2011), with two studies from Canada (Oloo, 2007; Bingham et al., 2014) and two from New Zealand (Hall et al. 2013; \& Bennett et al., 2002). One of the Canadian studies recruited participants across the south west of the United States of America (Bingham et al., 2014) and another study recruited participants from the Australasian region (Asmar et al., 2011).

Indigenous students were either surveyed or interviewed as individuals or in focus groups. Different demographic data were collected. The Indigenous voice is heard in 14 of the included research papers and involved Indigenous students, stakeholders, Indigenous community leaders and Indigenous staff members. Indigenous students revealed that having positive relationships with faculty contributed to their sense of satisfaction with their program of study and enabled them to more successfully navigate through their academic experience.

The number of included university sites ranged from 4 to 40 . Two studies also included nonIndigenous participants (Oloo, 2007; West et al., 2014). The gender of participants was reported in five papers (Bennett et al 2002; Bingham et al., 2014; Hall et al 2013; Oloo 2007; West et al 2014). These studies all reflected a similar ratio of female to male Indigenous students as reported in the Australasian 
survey of student engagement (Asmar Page \& Radcliff 2011). Compared to their non-Indigenous counterparts, Indigenous students were more likely to be predominantly female (Asmar Page \& Radcliff 2011). Furthermore, most participants acknowledged being 'first in family' to attend a facility of higher education. An exception was the study by Day et al (2009) who reported that nine out of the 12 participants interviewed were second-generation university students.

\section{Representation of other}

Representation of 'other' acknowledges different worldviews and affirms the importance of cultural support. Representation of other validates participants' experiences in their own words and different cultural ways of being are acknowledged and validated (Bilic, 2012). This was evident in a number of papers and was often demonstrated by the inclusion of Aboriginal community members or elder representation on the research team (Adams et al. 2005; Kippen et al. 2006; DiGregorio et al. 2000; Oliver et al. 2013; Hall et al. 2013). Conversely, the notion of being 'culturally different' was also described as a negative by participants. Cultural difference was described as 'being treated differently', being seen as different, experiencing racism, and compared in undesirable ways to non-Indigenous students (Hall et al. 2013; Bennett, 2002; West et al. 2014; Usher et al. 2005; DiGregorio et al. 2000).

The importance of family and connection to community were noted as crucial to the success of Indigenous students (Kippen et al. 2006; Usher et al., 2005; West et al. 2013; Day et al. 2009; Bingham et al. 2014). Most authors also confirmed the importance of cultural, financial \& academic support students gained from IESU's. The existence of these units was associated with improved student success, retention and engagement if an adequate level of support was received (Oliver et al., 2013; Pechenkina et al., 2011, West et al., 2014; Day \& Nolde, 2009).

\section{Ways of Knowing}

Shared knowledge and common experiences inform ways of knowing. An oppressed group share the experience of problems faced when living outside the dominant culture (Bilic, 2012). From a positive perspective, ways of knowing enables Indigenous people to represent themselves and be acknowledged as different (Moreton-Robinson, 2013, Martin, 2008). The provision of culturally safe teaching approaches and learning spaces are examples of strategies that recognise ways of knowing. Additionally, Standpoint Theory acknowledges that an oppressed person may have a distinct viewpoint that is privileged because she/he has heightened insights. Participants in most of the included studies described the importance of inclusion, valuing Indigenous content and knowledge in curricula, and presenting the truth about history and impact of colonisation. A clear, respectful presence of Indigenous culture throughout their time at university was seen as protective of Indigenous student success. Conversely, participants in a number of papers described being surprised and offended about lack of respect for Indigenous culture and knowledge in courses (Digregorio et al. 2000; Oloo 2007; Kippen et al. 2006; Usher et al. 2005; Oliver et al. 2013).

\section{Heterogeneous experience}


Heterogeneous experience acknowledges that knowledge ‘starts from participants’ lives’ (Bilic, 2012) and recognises the responsibility of higher education institutions in creating a welcoming environment. In order to gain an Indigenous student standpoint, 12 studies interviewed participants. The motivation of many participants to enrol in higher education programs came from the influence of their communities, being first in family to attend University, and potential for financial security through increased earnings from a professional career. A strong motivation to succeed in order to 'make a difference' and better themselves were also described (Adams et al. 2005; Usher et al. 2005; Asmar et al. 2011; Hall et al. 2013). Bennett (2002) described the importance of building links between westernised education and Māori heritage that would foster cultural security. Similarly, Hall et al., (2013) acknowledged the importance of teaching students how to learn in a different cultural environment. West et al (2011) further recommended strategies (such as peer mentoring and building secure relationships) to ensure Indigenous students utilised all possible support mechanisms available across the university as well as those provided by IESU's.

\section{Ways of Doing}

Ways of doing are informed by being and knowing. By listening, hearing and observing, a researcher can become cognisant of the knowledges and experiences of participants, and can reflect on what they have been told and why it is important (Moreton-Robinson, 2013). Research that starts from the 'everyday life' of participants or the oppressed group will lead to knowledge claims that are less partial and distorted than those of the dominant group, this perspective was described by Harding (2004) and Bilic (2012) as strong objectivity.

\section{Strong objectivity}

Methodologies that collected data by interviews with Indigenous students about their experiences in higher education often used purposive sampling approaches. Interviews were used in 12 of the included studies. DiGregorio et al., (2000) inductively analysed interview data and checked with participants to confirm the 'correctness' of the analysis. Similarly, the environment and place of interviews were considered important (Usher et al. 2005; Bingham et al., 2014). Plater (2013) stated that her professional knowledge of teaching Indigenous students in academia enriched her understanding of the data. Oliver et al. (2013) used a mixed methods approach and triangulated responses to an online survey with interview data to increase the richness of findings. West et al., (2011) also used a mixed methods approach as well as a secondary analysis of student interviews using narrative analysis to enhance objectivity.

\section{Reflexivity}

Reflexivity helps researchers to see participants’ knowledge as empowering (Bilic 2012). NonIndigenous researchers face challenges when exploring the experiences of Indigenous students. Reflexivity from Standpoint Theory acknowledges that one's own knowledge and experiences are partial and situated (Bilic, 2012). Reflexivity can also be conceptualised as the researcher being cultural respectful and safely manage the knowledge gained from participants. Only one researcher 
positioned herself as an Aboriginal woman (West et al. 2014). In a number of included studies, reference was made to the importance of Indigenous community input in the research process (Adams et al., 2005; DiGregorio, Farrington \& Page, 2000; Kippen et al., 2006; Oliver et al., 2013). In another research paper, the reflexive process involved a female member of the research team interviewing female college students from culturally diverse backgrounds (Bingham et al., 2014).

Strategies to enhance trustworthiness of the data analysis included integrating the researchers' experience with data analysis (Day et al. 2009), writing down their impressions of interviews and reflecting critically on their reactions to participants' stories (Plater 2013), crosschecking between team members (Usher et al. 2005), inductive thematic analysis (Hall et al. 2013), and using the university database as a cross-reference for data collected from participants (Bennett, 2002).

\section{Double consciousness}

Double consciousness is described by Hook (2004) as a way of 'looking from the outside in and from the inside out' and has the potential to affect societal change for the better. The Standpoint Theory framework also includes the notion of 'double consciousness' which is the heightened awareness of one's own life and life of the dominant group. For example, some authors reported that many participants described the necessity of being well versed in their own Indigenous culture as well as that of the dominant culture (Bingham et al, 2014; Oliver et al, 2013).

It is important to see the standpoint of participants in order to understand the impact of the dominant culture in higher education (Usher, et al., 2005). This standpoint was described in a number of studies as 'vulnerability', a tension between the person's own cultural experience, and the novelty of the learning environment. Some Indigenous participants valued smaller teaching spaces and extra academic support (Kippen et al., 2006; Asmar et al. 2011; Bennett 2002). A number of researchers commented that new policies, institutional structural change, and commitment to social equity would help support Indigenous student success (Kippen et al., 2006; Oliver et al., 2013; West et al., 2014).

\section{Navigating outsider/insider}

Notions of insider/outsider include the role of the researcher as an outsider looking into a worldview of the participant, how this is managed, and consideration of issues from the standpoint of the oppressed group. Bilic (2012) described the outsider/insider standpoint as positioning herself as the researcher, while simultaneously being an outsider from the oppressed group she was researching. From the participant perspective, Indigenous students noted that academics lacked an understanding from their worldview, which sometimes created barriers to learning (Usher et al., 2005). Academics who had a conscious awareness of their position were able to facilitate a more culturally safe learning environment and promote student success (Usher et al., 2005).

In a number of studies, participants described their concerns about a perceived lack of knowledge about 'things Indigenous', perceived disinterest and aloofness of academic faculty, and failure to recognise 
the importance of cultural needs (Oloo 2007; Kippen et al. 2006; Usher et al. 2005; Oliver et al. 2013; West et al. 2014; Hall et al. 2013). Conversely Asmar et al., (2011) found that Indigenous students reported positive interactions with faculty.

\section{Discussion}

This review aimed to evaluate interventions to improve Indigenous student success and resilience from a Reframed Standpoint Theory perspective. Much of the literature to date describes issues and identifies strategies, however, studies that test the efficacy of these interventions were rare. Multifaceted, multi-layered support was found to be crucial for Indigenous student success but there was little evidence of integration of support strategies throughout the student journey. This discussion links components of the Reframed Standpoint Theory with the identified elements of success. These include cultural, academic and financial support, as well as the relevant principles of respect, relationships, and responsibility for Indigenous student success.

\section{Cultural Support}

Indigenous students need support from multiple sources and organisations such as other Indigenous students, their family, and communities, as well as schools, faculties, universities and professional bodies. For many Indigenous students' relationships and connectedness are foundational to their culture. Acknowledging Indigenous students' knowledge as a heterogeneous experience recognises diversity as well as the strong influence and importance of community. This review found that support from family, community and other students/peers was pivotal to student success.

Cultural support was found to be best placed inside IESU's with links to schools and faculties. This finding is reinforced in a number of government reports that made commentary about the important influence of IESU's. Students reported a number of positive benefits from the IESU's however the specific elements that lead to success remain largely unknown. Representation of 'other' could offer insight into the success of IESU's for Indigenous students by offering a different representation of the university world that meets their specific needs. The level of support offered by IESU's ranged from cultural, emotional and counselling support especially when coping with racism.

Given the diverse overwhelming needs reported by participants across all studies, it is imperative that IESU's are well resourced, tailored to meet the unique needs of Indigenous students, and can provide a holistic approach to support. Successful IESU's require commitment from universities at all levels as well as guidance from members of the relevant Indigenous communities. Clear guidelines and strong partnerships with individual schools, academics and university wide are paramount (West et al, 2011). With these aspects in mind, and through the lens of double consciousness (looking from the outside in and inside out) IESU's in a partnership model with schools and faculties need the resources and have the capacity to be involved in recruitment and enrolment of students; assessment and support of "at risk” students, and the ability to provide mentoring and positive role models. 


\section{Financial Support}

Practical support primarily needs to address financial demands of students' academic, literacy, travel, and living costs. Financial hardship had a significant impact on Indigenous students' ability to continue in their program of study, most researchers recommended support in the form of scholarships, especially to assist with the purchase of books, computers and travel when away from home. The financial burden was also described as having a cultural component in that often students were working part time while studying in order to help support their family back home. Financial hardship also had a gender component (a way of being), as statistically more Indigenous students in higher education are female and are more likely to have carer and cultural responsibilities (a way of doing) including providing financial support to others. Authors debated the source of financial support across studies and recommendations included the need for financial support from government, universities, Indigenous communities and philanthropic sources.

\section{Academic Support}

Practical support to address the academic needs of Indigenous students was often mentioned. Indigenous students tend to be 'first in family' to attend universities (way of being \& heterogeneous experience). They often come into higher education through alternative pathways and do not have the same insights and academic preparation as non-Indigenous students (navigating outsider/insider). Indigenous students expressed feeling unfamiliar with university systems and often did not understand the prescriptive academic writing styles required in all academic departments (double consciousness). In Australia universities have received funding from the Federal Government to provide individual tutorial support to Indigenous students, however, in recent years funding cuts by successive governments have limited these services (Holland, 2015).

\section{Respect}

Issues related to respect were conceptualised as cultural respect, safety, and racism. Indigenous students reported wanting their culture honoured and preserved. Indigenous students wanted to feel culturally safe and not be exposed to racism. It is important to take these complex issues into consideration for Indigenous students' success in higher education. Academics, administration staff and peers have significant impact on Indigenous students' safe journey through their educational experience. Offering on-going professional development for academic staff may assist in consciousness raising the worldview of the student and their 'outsider' position.

A clear respectful presence of Indigenous culture throughout the university and in academic programs was seen as protective of resilience in Indigenous students. Programs such as 'Strengthening of Cultural Identity' have been used as a primary prevention strategy against poor academic achievement in Māori students in New Zealand/ Aotearoa (Bennett, 2002).

Culturally appropriate contributions by academics can also make a difference. It is equally important that academics are well supported, and any issues associated with a lack of cultural awareness are 
addressed promptly. West et al., (2013) concluded that faculty who are respectful and acknowledge Indigenous culture have the potential to significantly influence successful outcomes for Indigenous students. If academics are reflexive they are able to see how empowering Indigenous student knowledge can make a difference in the classroom and in the eyes of other students.

Many of the studies reviewed reported on culturally unsafe teaching practices and Indigenous students' perceptions of being treated differently in adverse ways. Some Indigenous students experienced and reported racism from academics and other students (representation of other). Everyone has a responsibility to ensure and contribute to an educational environment that is built on cultural respect and safety. Transformative teaching methods will increase Indigenous students' resilience when dealing with these challenging situations. Additionally, academics in health programs have a duty of care in the provision of culturally safe clinical practice experiences for students. There is a lack of research examining Indigenous students' experiences in the clinical practice area. Given approximately 50 percent of health program content involves clinical practice, awareness of students' experience in this context is essential to their academic success.

\section{Relationships}

Indigenous students expressed satisfaction about their education when they had positive relationships with academics and other students. West (2011) identified that Indigenous students require a different sort of relationship with academics. When faculty are sensitive to students' needs, students are more likely to successfully navigate their way through the system. Many Indigenous students reported experiences of a one-way, didactic educational process that did not meet their needs. Indigenous students are more engaged with their learning when interactions with teachers are flexible and less traditional. They want academic staff to honour and recognise the importance of family issues and commitments and have a flexible approach to support these values (way of being \& way of knowing). Indigenous students endorse blended approaches to delivery of programs, as these approaches enable them to attend their studies from their home communities. Offering teaching in short intensive blocks of time can also enable Indigenous students to integrate their learning with work and family commitments. Nursing and midwifery degrees in New Zealand, Canada and Australia are increasingly being offered in flexible ways.

\section{Responsibility}

Higher education institutions have a responsibility to Indigenous students in creating a welcoming environment that honours and celebrates their culture. In a number of included papers, Indigenous students described the notion of having to live or try to negotiate living in 'two-worlds'. Universities have a responsibility to offer Indigenous students a seamless admission process, academic support and systems that enable progress and completion of programs. Indigenous students bring a richness to the higher education environment that needs to be acknowledged and valued. Findings from the standpoint element of double consciousness should prompt higher education facilities to recognise the impact of the dominant culture and have a heightened awareness of how this new environment can be 
challenging for Indigenous students. Policy guidelines also need to be actioned and resourced appropriately. Universities also need to build strong partnerships with professional bodies and industry partners as part of their responsibility to Indigenous students. Universities could offer education that respects Indigenous students for who they are and what is applicable to their worldview.

\section{Implications for Nursing and Midwifery Education}

Evidence from this review indicates that nursing and midwifery education in countries with Indigenous populations are yet to offer programs that are culturally safe for Indigenous students. A culturally safe nursing or midwifery program would embed Indigenous knowledge and pedagogy in courses as well as offer Indigenous specific courses that expose students to the impact of colonisation on the health and wellbeing of Indigenous peoples. Nursing and midwifery education must provide culturally safe learning environments for Indigenous students in both the academic learning space and in clinical practice. Across the studies reviewed students spoke of unsafe environments where racism was a common experience. Schools of nursing and midwifery education need to adopt policies, guidelines and actions that provide cultural safety training for academics, clinicians and other students, so that Indigenous students feel valued and feel connected to their chosen profession. Furthermore, schools and universities have a role to play in connecting students to their respective nursing and midwifery professional bodies. The role of professional groups needs to be visible to students in their transition from student to beginning practitioner, and as part of their future career. Similarly, competencies and standards for practice need to value a diverse, culturally safe and competent workforce.

\section{Limitations}

There are limitations associated with this integrative review. The first author comes from a position of cultural responsiveness and has been influenced by cultural knowledge and experience of biculturalism gained from being born, raised and working within the midwifery profession in New Zealand where cultural respect and competence forms part of everyday working life. The review team were all female and included an Australian Aboriginal woman and these combined perspectives may have affected the conclusions of the review, hopefully in positive ways.

The review only accessed papers published in English and some work outside of non-English speaking countries may not be published. There is some likelihood that not all appropriate studies were located if they were not presented in indexed journals. The qualitative nature of the majority of included papers meant that some databases were less effective in the search. For example, Web of Science has a predominance of quantitative studies in journals with an impact factor. A number of Government reports were used as reference material from Australia and New Zealand; however, access to Government reports from other countries could not be easily obtained, limiting the generalisability of results.

\section{Conclusions}


This integrative literature review critiqued studies by using a framework that acknowledged differences within the research process and enabled new insights about the success and resilience of Indigenous students in undergraduate nursing and midwifery programs in higher education. Although a number of factors appear to impact of the success of Indigenous students the most crucial factor is one of support. Support for Indigenous students’ needs to be multi-layered and multi-faceted. Indigenous students are more successful when they have the support of their communities and families and their 'way of being, knowing \& doing' is acknowledged as a right and equity issue. As evidenced in the literature students attending universities with IESU's are more likely to report receiving mentorship and have positive relationships with 'others', as well as strong cultural, and academic support. Furthermore, Indigenous students who are financially resourced do better. Indigenous students want their culture visible to them, within curricula and within the policies and guidelines of the institution. They want to be valued, feel culturally safe in the learning environment and be able to navigate the 'two worlds' in a restorative manner.

In conclusion further research is required that examines interventions that measure success for undergraduate Indigenous students. Higher education institutions need to take a conscious and deliberate approach to the challenge of incorporating multi-dimensional support of Indigenous students and make a commitment to acknowledge and incorporate Indigenous knowledges and cultures into curricula. Higher education institutions need to support the provision of professional development for staff in cultural safety programs. Improving the academic success and resilience of Indigenous students in higher education has the potential to be transformative for Indigenous students as well as other students and ultimately impact on health care practices and outcomes for the community. 


\section{References}

Adams, M., Aylward, P., Heyne, N., Hull, C., Misan, G., Taylor, J., \& Walker-Jefferys, M. (2005). Integrated support for Aboriginal tertiary students in health-related course: the Pika Wiya Learning Centre. Australian Health Review, 29(4), 482-488. https://doi: 10.1071/AH050482

Asmar, C., Page, S., \& Radloff, A. (2011). Dispelling myths: Indigenous students' enagement with university research briefing Australiasian Survey of Student Engagement 10 (April): 1-16. Melbourne, Australia. Rretrieved from http://www.acer.edu.au/files/AUSSE_Research_Briefing_Vol10.pdf

Australian Institute of Health and Welfare. (2015) Aboriginal and Torres Strait Islander Health performance framework data. Canberra, Australia: Author retrieved from http://www.aihw.gov.au/indigenous-data/health-performance-framework/.

Behrendt, L., Larkin, S., Griew, R., \& Kelly, P. (2012). Review of higher education access and outcomes for Aboriginal and Torres Strait Islander people: Final report (pp. i - xvii and 1 275). Canberra ACT: Australian Government.

Bennett, S. (2002). Cultural identity and academic achievement among Māori undergraduate univeristy students. Paper presented at the National Māori Graduates of Psychology Symposium: Making a difference, 29-30 November. Hamilton, New Zealand.

Bilic, S. (2012). Researching minority culture woman's standpoint and experiences of rights. Proceedings of a conference held 22-24 November 2011 at The Cultural Studies Association of Australasia, Adelaide Australia:

Bingham, J., Bearchief Adolpho, Q., Jackson, A., \& Alexitch, L. (2014). Indigenous women college students' perspectives on college, work \& family. Journal of College Students Development, 55(6), 615 - 632. https://doi: 10.1353/csd.2014.0055

Commonwelath Department of Education. (2012). Review of Higher Education Access and Outcomes for Aboriginal and Torres Strait Islander People: Final Report (pp. 273). Canberra, Australia:

Commonwealth Department of Education. (2013). Summary of the 2013 first half year higher education student statisitcs. Canberra, Australia. Retrieved from https://docs.education.gov.au/system/files/doc/other/2013_first_half_year_student_summary.p df.

Craven, R., \& Dillon, A. (2013). Seeding success in indigenous Australian higher edcuation: Indigneous Australians students' particpation in higher edcuation and potential ways forward. Seeding Success in Indigenous Australian Higher Edcaution Diversity in Edcuation, 14, 3-27. Emerald Group Publishing Ltd. Retrieved from https://doi.org/10.1108/S14793644(2013)0000014001.

Critical Appraisal Skills Programme (CASP) 2014.

CASP Checklists, Retrieved from http://www.casp-uk.net/\#!/cd2g, Oxford. CASP.

Curtis, E., Wikaire, E., Lualua-Aati, T., Kool, B., Nepia, W., Ruka, M., Honey, M., Kelly, F., \& Poole. P. (2012). Tatou Tatou success for all: Improving Maori student success. Ako Aotearoa: National Centre for Tertiary Teaching Excellence. Retrieved from 
https://akoaotearoa.ac.nz/download/ng/file/group-1652/tatou-tatou--success-for-allimproving-maori-student-success.pdf

Day, D., \& Nolde, R. (2009). Arresting the decline in Australian Indigenous representation at university; Student experience as a guide. Equal Opportunities International, 28(2), 135-161. https://doi: 10.1108/02610150910937899

DiGregorio, K. D., Farrington, S., \& Page, S. (2000). Listening to our students: Understanding the factors that affect Aboriginal and Torres Strait Islander students' academic success. Higher Education Research \& Development, 19(3), 297-309. https://doi: 10.1080/758484344

Government of New Zealand. (2014). Tertiary Education Strategy 2014-2019: Ministry of Education \& Ministry of Business, Innovation and Employment. Wellington, New Zealand.

Government of British Columbia. (2013). Aboriginal post secondary education and training policy framework and action plan: 2020 vision for the future. Ministry of Advanced Education. Vancouver, Canada: Retrieved from http://www.aved.gov.bc.ca/aboriginal/docs/Aboriginal_Action_Plan.pdf.

Hall, M., Rata, A., \& Adds, P. (2013). He Manu Hou: The Transition of Maori Students into Maori Studies. International Indigenous Policy Journal, 4(4). Retrieved from: http://ir.lib.uwo.ca/iipj/vol4/iss4/7

Harding, S. (Ed.). (2004). The feminist Standpoint Theory reader: Intellectual and political controversies. New York: Routledge.

Hossain, D., Gorman, D., Williams-Mozely, J., \& Garvey, D. (2008). Bridging the gap: Identifying needs and aspirations of Indigenous students to facilitate their entry into university. The Australian Journal of Indigenous Education, vol. 37, 9-17.

Kippen, S., Ward, B., \& Warren, L. (2006). Enhancing Indigenous participation in higher education health courses in rural Victoria. Australian Journal of Indigenous Education, vol. 35, 1-10.

Martin, K. (2008). Please knoeck before you enter: Aboriginal regulation of outsiders and the implications for researchers. Post Pressed, Teneriffe, Queensland.

Ministry of Health. (2012). First Nations and Inuit health strategy plan: A shared path to improve health. Authour, Ottawa, Canada. retrieved from http://www.hc-sc.gc.ca/fniahspnia/pubs/strat-plan-2012/index-eng.php

Moreton - Robinson, A. (2000). Talkin' up to the white woman: Indigenous women and feminism. Queensland, Australia: University of Queensland Press.

Moreton-Robinson, A. (2013). Towards and Australian Indigenous Women's Standpoint Theory. Australian feminist Studies, 28(78), 331-347. https://doi 10.1080/08164649.2013.876664

Moher D, Liberati A, Tetzlaff J, Altman DG, The PRISMA Group (2009) Preferred Reporting Items for Systematic Reviews and Meta-Analyses: The PRISMA Statement. PLoS Med 6(7): e1000097. https://doi:10.1371/journal.pmed.1000097

New Zealand Ministry of Health. (2014). Annual update of key results 2013/2014: New Zealalnd Health survey. Author, Wellington,. Retrieved from http:/www.health.govt.nz/publication/annual-update-key-results-2013-14-new-zealandhealth-survey. 
Oliver, R., Rochecouste, J., Anderson, R., Cooper, I., Forrest, S., \& Excell, M. (2013). Understanding Australian Aboriginal tertiary student needs. International Journal of Higher education, 2(4), 52-64. https://doi: 10.5430/ijhe.v2n4p52

Oloo, J. (2007). Aboriginal university student success in British Columbia, Canada: time for action. The Australian Journal of Indigenous Education, 36, 88-100.

Papps, E., \& Ramsden, I. (1996). Cultural Safety in Nursing: the New Zealand Experience. International Journal for Quality in Health Care, 8 (5): 491-497. Retrieved from: http://intqhc.oxfordjournals.org/content/intqhc/8/5/491.full.pdf

Pechenkina, E., Kowal, E., \& Paradies, Y. (2011). Indigenous Australian students' participation rates in higher education: exploring the role of universities. The Australian Journal of Indigenous Education, 40, 59-68. https://doi: 10.1375/ajie.40.59

Plater, S. (2013). For the life of me, I can't see why those students were let go on so long: educating the educators, Aboriginal and Torres Strait Islander-style. The Australian Journal of Indigenous Education, 41(2), 156-161. https://doi: 10.1017/jie.2012.24

Rossingh, B., \& Dunbar, T. (2012). A participative evaluation model to refine academic support for first year Indigenous higher education students. The International Journal of the First Year in Higher Education, 3(1), 61-74. https://doi: 10.5204/intjfyhe.v3i1.113

Usher, K., Lindsay, D., Miller, M., \& Miller, A. (2005). Challenges faced by Indigenous nursing students and strategies that aided their progress in the course: a descriptive study. Contemporary Nurse, 10(1-2), 17-31. https://doi: 10.5172/conu.19.1-2.17

West, R., Usher, K., Buettner, P., Foster, K., \& Stewart, L. (2013). Indigenous Australians' participation in pre-registration tertiary nursing courses: A mixed methods study. Contemporary Nurse, 46(1), 123-134. https://doi: 10.5172/conu.2013.46.1.123

West, R., Usher, K., Foster, K., \& Stewart, L. (2014). Academic staff perceptions of factors underlying program completion by Australian indigenous nursing students. The Qualitative Report, 19(24), 1-19. Retrieved from http://www.nova.edu/ssss/QR/QR19/west24.pdf 